\title{
ANALISIS PROYEK PEMBANGUNAN TOWER TELEKOMUNIKASI DENGAN METODE CRITICAL PATH METHOD \\ ( Suatu Kajian Pada PT. Ciptajaya Sejahtera Abadi di Jakarta )
}

\author{
Hermanto ${ }^{1}$, Dadang J² \\ Hers3sm@gmail.com \\ Program Studi Teknik Industri Fakultas Teknik,Matematika dan IPA \\ Universitas Indraprasta PGRI
}

\begin{abstract}
Abstrak: suatu jaringan kerja yang cepat, tepat dan efisien, dalam melakukan penjadwalan waktu proyek yang dikerjakan dengan menggunakan metode CPM (Critical Path Method), dengan bantuan software microsoft project dan WinQSB-2 sehingga diperoleh waktu penyelesaian proyek yang optimal dengan biaya pelaksanaan dilapangan dapat di tekan serendah mungkin, tanpa mengurangi mutu pekerjaan. Metode Penelitian yang digunakan adalah metode pengembangan proyek, dengan penelitian yang bersifat kualitatif yang dikuantitatifkan yaitu mengumpulkan data sebanyak-banyaknya mengenai faktor-faktor yang merupakan pendukung dalam penelitian, kemudian menganalisis faktorfaktor tersebut untuk dicari peranannya sebagai perhitungan waktu penjadwalan proyek yang benar dan baik dalam melakukan suatu kegiatan yang dilakukan oleh PT. Ciptajaya Sejahtera Abadi. Setelah peneliti menganalisis data, akhirnya peneliti dapat menarik kesimpulan bahwa terdapat Alternatif waktu penjadwalan yang dipilih dengan menggunakan waktu yang optimal 36 hari, karena waktu penyelesaiannya lebih cepat 9 hari dari waktu normal dengan biaya crash

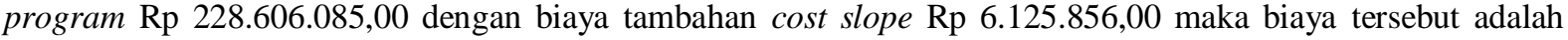
biaya yang optimal dengan waktu dan biaya yang lebih efisien dan efektif.
\end{abstract}

Kata Kunci: Proyek tower telekomunikasi, metode CPM, PT. CSA

\section{PENDAHULUAN}

Kemajuan teknologi jaringan komunikasi dan informasi semakin berkembang dan tumbuh semakin luas dan beraneka, dengan banyaknya pengguna telepon selular yang terus berkreasi dengan majunya teknologi baru, menimbulkan kurangnya sarana penunjang sistem telekomunikasi yang ada, maka perlu penambahan pembangunan sarana infrastruktur tower dan pedukungnya, agar konsumen tetap terjamin dan nyaman dalam menggunakan telepon selular yang semakin baik. Terkait dengan kondisi yang ada, diperlukan instansi-instansi yang bergerak untuk pembangunan dan pelaksanaan proyek. PT. Ciptajaya Sejahtera Abadi adalah kontraktor yang membangun berbagai macam tower dan sarana pendukungnya. Dalam melakukan kegiatan eksploitasi dan eksplorasi PT. Ciptajaya Sejahtera Abadi saat memperkirakan waktu dan biaya yang dibutuhkan hanya berdasarkan pengalaman saja. Maka hal ini akan mengakibatkan pihak manajemen sulit untuk mengontrol jalannya proyek, yang akhirnya akan mempengaruhi penyelesaian proyek secara keseluruhan. Sehubungan dengan hal tersebut. Maka peneliti menganalisis proyek pembangunan tower telekomunikasi dengan metode CPM (Critical Path Method) untuk mendapatkan waktu dan biaya yang lebih efektif dan efisien.

\section{Landasan Teori}

\section{Manajemen Proyek}

Sebuah proyek merupakan rangkaian tugas dan aktivitas yang memiliki suatu tujuan tertentu yang harus diselesaikan sesuai dengan waktu, biaya dan spesifikasi yang telah ditetapkan. Manejemen proyek adalah pengelolaan suatu proyek yang mencakup proses pelingkupan, perencanaan, penyediaan staf, pengorganisasian, dan pengontrolan suatu proyek. Menurut Reksohadiprodjo (1984:8). 


\section{a. Unsur Pokok Manajemen Proyek}

Adapun unsur pokok tersebut meliputi :

1) Tujuan Proyek Proyek: umumnya merupakan suatu aktivitas yang berlangsung dalam waktu tertentu dengan hasil akhir tertentu.

2) Kompleksitas Proyek: Pengelolaan proyek melibatkan beberapa fungsi organisasi seperti pemasaran, personalia, engineering, produksi dan keuangan.

3) Keunikan Proyek: Setiap pekerjaan proyek mempunyai karakter tersendiri akan berbeda dari apa yang pernah dilakukan meskipun bentuk proyek sama atau rutin dilakukan.

4) Proyek merupakan kegiatan sementara: Proyek adalah suatu aktivitas yang bersifat temporer, organisasi dibentuk sementara untuk mengelola personalia, material dan fasilitas.

5) Resiko Proyek: Proyek umumnya menggunakan teknologi baru dan memiliki resistensi yang tidak pasti dan beresiko, kegagalan suatu proyek bisa berakibat buruk bagi organisasi.

6) Siklus Hidup Proyek: Proyek merupakan suatu proses bekerja dalam mencapai suatu tujuan dan selama proses proyek akan melewati beberapa fase yang disebut dengan "project life cycle".

7) Tipe Proyek:

a) Proyek yang berasal dari klien yang ditawarkan ke suatu konsultan atau kontraktor.

b) Ide proyek muncul karena ada tawaran dana dari instansi atau lembaga tertentu.

c) Proyek muncul karena adanya tawaran lelang.

d) Proyek berasal dari dalam perusahaan sendiri.

\section{b. Fungsi Manajemen Proyek}

Fungsi dasar manajemen proyek adalah pembatasan, perencanaan, perkiraan,penjadwalan, pengorganisasian, pengarahan, pengendalian dan penutupan:

1) Pelingkupan (Scooping); 2).Perencanaan (Planning) ; 3).Perkiraan (Estimating) .

4) Penjadwalan (Scheduling); 5).Pengorganisasian (Organizing); 6).Pengarahan (Directing); 7). Pengontrolan (Controlling); 8).Penutupan (Closing).

Fungsi-fungsi diatas tergantung pada komunikasi antar personal yang berkesinambungan di antara para manajer proyek, tim dan manajermanajer yang terlibat.

\section{c. Pengetahuan Manajemen Proyek}

Untuk mengelola aspek pengetahuan manajemen proyek, maka ada beberapa prinsip yang perlu diketahui atau difahami terlebih dahulu, yaitu:

1) Prinsip 1: Melakukan aktivitas terkait terhadap konsep kelompok proses yang ada.

2) Prinsip 2: Setiap kelompok proses membutuhkan sejumlah input (masukan) untuk menjalankan proses.

3) Prinsip 3: Saat proses berlangsung akan melibatkan sejumlah perangkat (tools) dan metode (teknik) pekerjaan yang memadai.

4) Prinsip 4: Hasil output (keluaran) dari proses akan dipergunakan untuk pelaksanaan kelompok proses pada aspek pengetahuan manajemen proyek yang lain.

Kelompok proses yang digunakan dalam manajemen proyek, terdiri atas :

1) Proses Inisiasi (penjajagan), kesediaan para stakeholders dalam menjalankan proyek.

2) Proses Perencanaan, perencanaan terhadap kebutuhan pelaksanaan proyek (S-TQC).

3) Proses Pengolahan, pelakasanaan pekerjaan oleh sumber daya yang ada dalam proyek.

4) Proses Pengendalian, pengawasan yang obyektif terhadap seluruh pekerjaan proyek.

5) Proses Penutupan, persetujuan formal terhadap hasil output dari pekerjaan proyek. 


\section{d. Tahapan dalam Kegiatan Proyek}

Kegiatan proyek dikelompokkan dalam dua tahap, yaitu tahap persiapan dan tahap Kegiatan utama dalam tahap persiapan adalah

1) Identifikasi gagasan proyek atau analisa pendahuluan

2) Evaluasi kelayakan konsep alternative dari semua aspek

3) Pentuan konsep alternative terbaik

4) Identifikasi sumber daya yang diperlukan dan jadwal pelaksanaan

5) Menyusun perkiraan biaya

6) Menyusun organisasi pelaksanaan

Tahap pelaksanaan ditandai dengan kegiatan proyek, yaitu rekayasa desain, pengadaan material, dan kegiatan kontruksi. Tahap pelaksana mencakup :

1) Menyiapkan rincian rekayasa desain untuk pengadaan material dan kontruksi.

2) Menyusun anggaran definitif dan jadwal induk proyek.

3) Pengadaan dan mobilisasi tenaga kerja.

4) Pembelian kontruksi, pra-operasi dan start-up.

\section{METODOLOGI PENELITIAN}

\section{1) Tempat Penelitian}

Tempat penelitian dilakukan pada PT. Ciptajaya Sejahtera Abadi, Jl.Balai Pustaka Barat No. 329A Jakarta 13220. Dalam penelitian yang dilakukan yaitu penelitian terhadap proyek pembangunan tower $72 \mathrm{~m}$ untuk pengembangan jaringan telekomunikasi yang berlokasi di Sesaot-Lombok, pembangunan proyek tersebut telah selesai dilaksanakan pada bulan Mei sampai Juli 2010 dengan nilai kontrak Rp 462.458.711,00.

\section{B. Metode Penelitian}

Metode penelitian tentang proyek pembangunan tower telekomunikasi ini menggunakan metode pengembangan proyek, dengan penelitian yang bersifat kualitatif yang dikuantitatifkan yang diperoleh melalui data lapangan, yaitu data yang pasti yang merupakan data sebenarnya dan tampak. Peneliti melakukan pengumpulan data dari hasil kegiatan kerja serta observasi dilapangan, hasil wawancara dan dokumentasi yang ada pada PT. Ciptajaya Sejahtera Abadi tentang pelaksanaan proyek pembangunan tower $72 \mathrm{~m}$ yang berlokasi diSesaot-Lombok. Dengan demikian peneliti melakukan network plan dengan metode CPM (critical path method) dan bantuan software microsoft project dan win QSB-2 (Quattitativ System for Business) untuk memperoleh alternative penjadwalan waktu proyek dalam jaringan kerja yang cepat, tepat dan efisien dengan waktu dan biaya yang optimal. Maka dengan demikian masalah yang dihadapi dapat dianalisis dan dipecahkan dengan baik sesuai yang diinginkan. Dan dapat dilihat dalam penggambaran kerangka pemecahan masalah pada Gambar 10. Flow Chart Metode Penelitian.

\section{Metode Pengumpulan Data}

Dalam pengumpulan data peneliti melakukan pendataan data kegiatan kerja dan observasi dilapangan sebagai berikut :

1). Studi Lapangan : 2). Wawancara

Dari teknik pengolahan data yang dilakukan, didapatkan dua jenis data yaitu :

a. Data Primer adalah data yang didapat dari penelitian langsung di lapangan dengan melihat kegiatan pekerjaan yang sedang berlangsung.

b. Data Sekunder adalah data yang didapat dari pihak perusahaan dalam bentuk dokumen-dokumen. 


\section{Teknik Analisis Data}

Data-data yang didapat selama penelitian tersebut selanjutnya dikelolah, dan untuk memperoleh informasi yang berguna dalam menyelesaikan masalah yang dihadapi dalam pengolahan data untuk penelitian, dilakukan langkahlangkah sebagai berikut :

1. Hasil penelitian dilakukan perhitungan waktu kegiatan dengan pendekatan metode CPM (Critical Path Method).

2. Merumuskan alternatif penjadwalan proyek yang mungkin dapat dilaksanakan.

3. Mengelola alternatif tersebut dengan langkah menjadwalkan proyek untuk membuat struktur uraian kegiatan dengan metode CPM (Critical Path Method), menganalisa penjadwalan masing-masing alternatif untuk proyek tersebut, dan membuat perbandingan biaya waktu normal dengan waktu pada saat dipercepat.

4. Pemilihan alternatif yang paling optimal berdasarkan hasil analisis untuk penjadwalan proyek, pembebanan tenaga kerja dan analisis total biaya proyek.

\section{HASIL PENELITIAN DAN PEMBAHASAN}

\section{Diagram Jaringan Kerja Dipercepat}

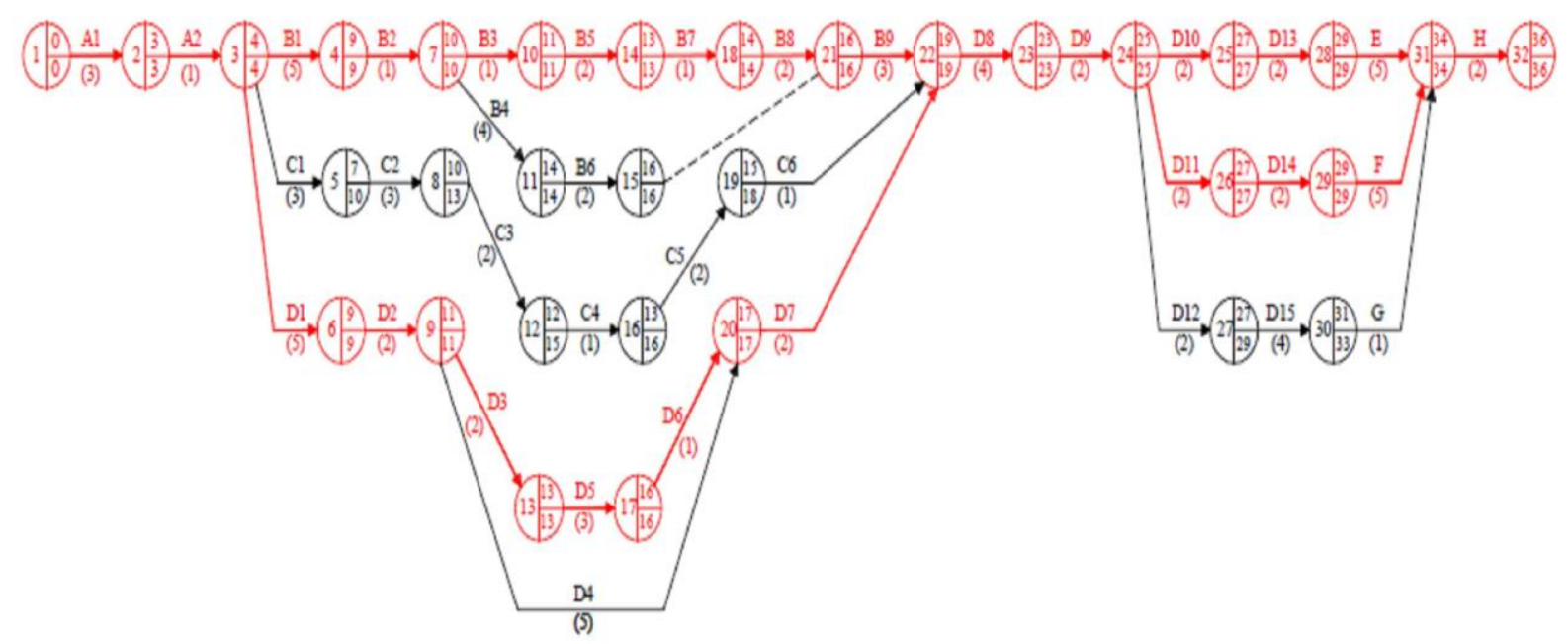

Maka hasil perhitungan dan jaringan kerja pada gambar 13 didapat lintasan kritis untuk waktu pelaksanaan dipercepat yaitu Lintasan Kritis : A1-A2-B1-B2-B3-B5-B7B8-B9-D1-D2-D3-D5-D6-D7-D8-D9-D10-D11-D13-D14-E-F-H

Untulk Pembanguman Tower Telekomumikasi dengan ketinggian $72 \mathrm{~m}$ bahwa

didapat Rencana Anggaran Biaya seperti pada tabel 18 .

Tabel 18. Rencana Anggaran Biaya (RAB)

\begin{tabular}{|c|c|c|c|}
\hline No & Uraian ISegiatan & Bobot (96) & Biaya (Fp) \\
\hline $\bar{I}$ & Biaya Langs ung & & \\
\hline$\overline{1}$ & Pekerjaan Persiapan + Bouvuplank & 1,91 & $4.250 .000,00$ \\
\hline 2 & Pekerjaan Pondasi Tower $72 \mathrm{~m}$ & 50,31 & $112.064 .300,00$ \\
\hline 3 & Pekerjaan Pondasi Shelrer & 3,80 & 8.453 .994 .00 \\
\hline 4 & Pekerjaan Pondasi Pagar & 23,29 & $51.889 .530,00$ \\
\hline 5 & Pekerjaan Pas. Paving Block & 14,67 & $32.674 .313,00$ \\
\hline 6 & Pekerjaan Jalan Masuk & 2,02 & $4.490 .000,00$ \\
\hline 7 & Pekerjaan Grouring (finishing tower) & 0,54 & $1.200 .000,00$ \\
\hline \multirow[t]{2}{*}{8} & Pekerjaan Pengecatan & 3,47 & $7.732 .475,00$ \\
\hline & Total Biava Langsung & 100,00 & 222.754 .612 .00 \\
\hline \multirow[t]{3}{*}{ III } & \multicolumn{2}{|c|}{ Biava Tak Langs ume ( 1096 dari baya hangumg) } & 22.275 .461 .20 \\
\hline & \multirow{2}{*}{\multicolumn{2}{|c|}{\begin{tabular}{|c|} 
Grand Total \\
\end{tabular}}} & \\
\hline & & & $245.030 .073,20$ \\
\hline
\end{tabular}


Tabel 20. Data Perbandingan Walktu dan Biaya

\begin{tabular}{|c|c|c|c|c|}
\hline $\begin{array}{c}\text { Kondisi } \\
\text { Waktu }\end{array}$ & Hari & Biaya Langsung & $\begin{array}{c}\text { Biaya Tidal } \\
\text { Langsung }\end{array}$ & Total Biaya \\
\hline$(1)$ & $(2)$ & $(3)$ & $(4)$ & $(5=4+3)$ \\
\hline Normal & 45 & $222.754 .612,00$ & $22.275 .461,20$ & $245.030 .073,20$ \\
\hline & & & & \\
\hline Crash & 36 & $228.606 .085,48$ & $22.860 .608,54$ & 251.466 .694 .02 \\
\hline
\end{tabular}

f. Kurva Biaya Proyels

Kurva waktu dan biaya proyek adalah gambar untuk memperjelas hubungan waktu pelaksanaan proyek dan biaya proyek seperti pada gambar 14.

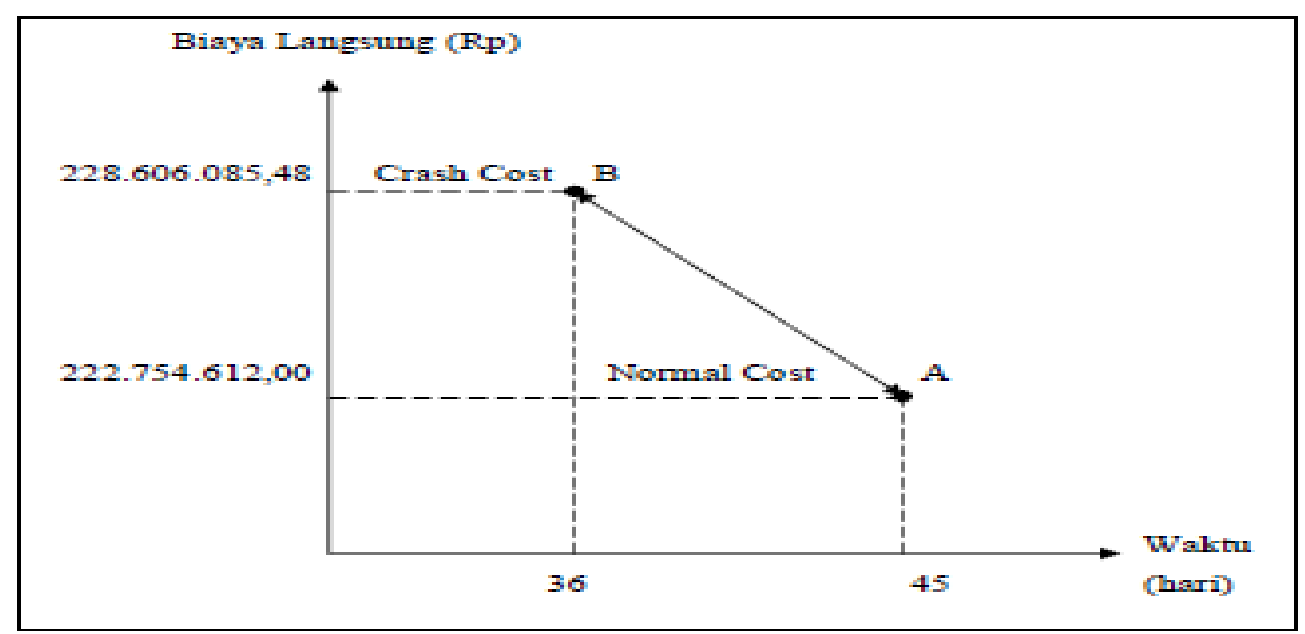

Gambar 14. Kurva Biaya Proyel

Keterangan :

Tirik A = Waktu dan Biaya Pada Kondisi Normal

Titik B : Walktu dan Biaya Pada IKondisi Optimal 


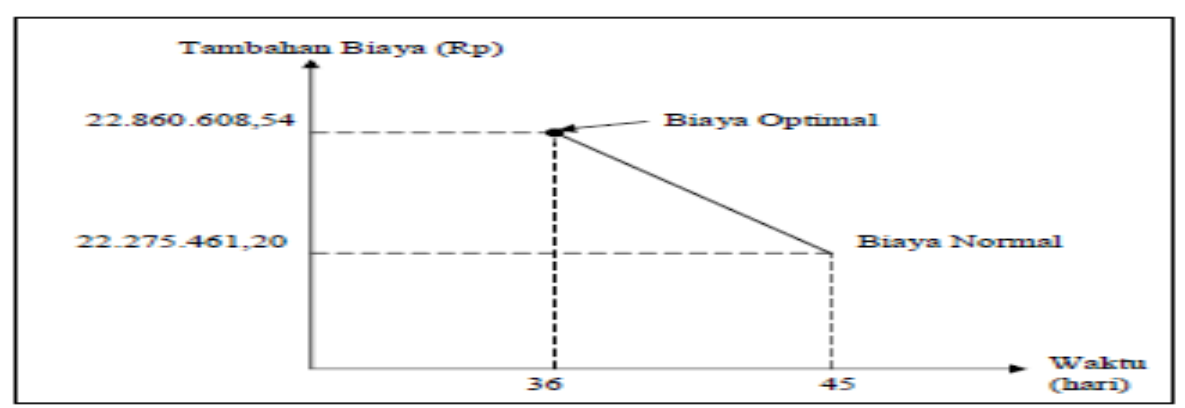

Gambax 15. Graful Hubungan Biaya Terhadap Walstu Optimal

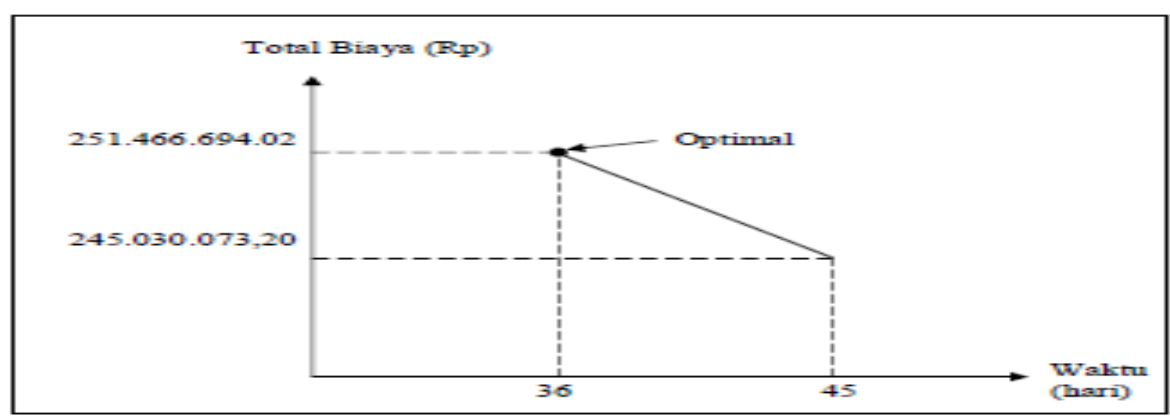

Gambax 16. Grafil Biaya Total Percepatan

g. Pengendalian Proyels

1) Persentase Biaya Normal

Tabel 21. Persentase Biaya Normal

\begin{tabular}{|c|c|c|c|c|}
\hline No & $\begin{array}{l}\text { Simbol } \\
\text { Kegiatan }\end{array}$ & $\begin{array}{c}\text { Wakru } \\
\text { (hari) }\end{array}$ & $\begin{array}{c}\text { Biaya Normal } \\
\text { (Rp) }\end{array}$ & $\begin{array}{c}\text { Bobot } \\
(\%)\end{array}$ \\
\hline 1 & A.1 & 4 & $2.250 .000,00$ & 1,01 \\
\hline 2 & $A 2$ & 2 & $2.000 .000,00$ & 0,90 \\
\hline 3 & $\mathrm{~B} 1$ & $\frac{2}{6}$ & $10.038 .600,00$ & 4,51 \\
\hline 4 & B2 & 1 & $301.400,00$ & 0,14 \\
\hline 5 & B3 & 2 & $1.507 .000,00$ & 0,68 \\
\hline 6 & B4 & 4 & $33.920 .000,00$ & 15,23 \\
\hline 7 & B5 & 2 & $2.430 .000,00$ & 1.09 \\
\hline 8 & B6 & 2 & $2.575 .000,00$ & 1,16 \\
\hline 9 & B7 & 2 & $15.375 .000,00$ & 6,90 \\
\hline 10 & B8 & 2 & $36.582 .000,00$ & 16,42 \\
\hline 11 & $\mathrm{B9}$ & 3 & $9.335 .300,00$ & 4.19 \\
\hline 12 & $C_{1}$ & 3 & $218.250,00$ & 0,10 \\
\hline 13 & $C_{2}$ & 3 & $2.324 .000,00$ & 1,04 \\
\hline 14 & $\mathrm{C} 3$ & 2 & $2.330 .000,00$ & 1,05 \\
\hline 15 & $C_{4}$ & 1 & $720.600,00$ & 0,32 \\
\hline 16 & $\mathrm{cs}$ & 2 & $1.719 .750,00$ & 0.77 \\
\hline 17 & $\mathrm{Co}$ & 1 & $1.141 .394,00$ & 0,51 \\
\hline 18 & D1 & 6 & $2.052 .000,00$ & 0,92 \\
\hline 19 & D2 & 2 & $936.000,00$ & 0,42 \\
\hline 20 & D3 & 3 & $960.000,00$ & 0,43 \\
\hline 21 & D4 & 5 & $10.800 .000,00$ & 4.85 \\
\hline 22 & D5 & 3 & $2.700 .000,00$ & 1,21 \\
\hline 23 & D6 & 2 & $1.140 .000,00$ & 0,51 \\
\hline 24 & D7 & 2 & $1.440 .000,00$ & 0,65 \\
\hline 25 & Ds & $\overline{6}$ & $5.206 .500,00$ & 2,34 \\
\hline 26 & D9 & 2 & $1.594 .430,00$ & 0,72 \\
\hline 27 & D10 & 2 & $1.465 .025,00$ & 0,66 \\
\hline 28 & DII & 2 & $786.000,00$ & 0,35 \\
\hline 29 & D12 & 2 & $767.100,00$ & 0,34 \\
\hline 30 & D13 & 3 & $1.579 .600,00$ & 0,71 \\
\hline 31 & D14 & 3 & $7.117 .875,00$ & 3,20 \\
\hline 32 & D15 & 4 & $13.345 .000,00$ & 5,99 \\
\hline 33 & $E$ & 5 & $32.674 .313,00$ & 14,67 \\
\hline 34 & F & 5 & $4.490 .000,00$ & 2,02 \\
\hline 35 & $G$ & 1 & $1.200 .000,00$ & 0,54 \\
\hline 36 & H & 3 & $7.732 .475,00$ & 3,47 \\
\hline \multicolumn{3}{|c|}{ Total } & $222.754 .612,00$ & 100,00 \\
\hline
\end{tabular}


Tabel 22. Persentase Biaya Percepatan

\begin{tabular}{|c|c|c|c|c|}
\hline No & $\begin{array}{c}\text { Simbol } \\
\text { Kegiatan }\end{array}$ & $\begin{array}{c}\text { Waktu } \\
\text { (han) }\end{array}$ & $\begin{array}{c}\text { Biaya Percepatan } \\
\text { (Rp) }\end{array}$ & $\begin{array}{c}\text { Bobot } \\
(\%)\end{array}$ \\
\hline 1 & A.1 & 3 & $2.770 .000,00$ & 1,21 \\
\hline 2 & A2 & 1 & $2288.880,89$ & 1,00 \\
\hline 3 & $\mathrm{BI}$ & 5 & $11.962 .933,33$ & 5,23 \\
\hline 4 & $\mathrm{~B} 2$ & 1 & $301.400,00$ & 0,13 \\
\hline 5 & $\mathrm{~B} 3$ & 1 & $1.694 .777,78$ & 0,74 \\
\hline 6 & B4 & 4 & $33.920 .000,00$ & 14,84 \\
\hline 7 & B5 & 2 & $2.430 .000,00$ & 1,06 \\
\hline 8 & B6 & 2 & $2.575 .000,00$ & 1,13 \\
\hline 9 & B7 & 1 & $15.813 .148,15$ & 6,92 \\
\hline 10 & B8 & 2 & $36.582 .000,00$ & 16,00 \\
\hline 11 & $\mathrm{Bg}$ & 3 & $9.335 .300,00$ & 4,08 \\
\hline 12 & $\mathrm{C}_{1}$ & 3 & $218.250,00$ & 0,10 \\
\hline 13 & $\mathrm{C}_{2}$ & 3 & $2.324 .000,00$ & 1,02 \\
\hline 14 & $\mathrm{C} 3$ & 2 & $2.330 .000,00$ & 1,02 \\
\hline 15 & $\mathrm{CA}_{4}$ & 1 & $720.600,00$ & 0,32 \\
\hline 16 & $\mathrm{Cs}$ & 2 & $1.719 .750,00$ & 0,75 \\
\hline 17 & $\mathrm{C6}$ & 1 & $1.141 .394,00$ & 0,50 \\
\hline 18 & D1 & 5 & $2.637 .666,67$ & 1,15 \\
\hline 19 & $\mathrm{D} 2$ & 2 & $936.000,00$ & 0,41 \\
\hline 20 & D3 & 2 & $1.176 .666,67$ & 0,51 \\
\hline 21 & D4 & 5 & $10.800 .000,00$ & 4,72 \\
\hline 22 & D5 & 3 & $2.700 .000,00$ & 1,18 \\
\hline 23 & D6 & 1 & $1.284 .444,44$ & 0,56 \\
\hline 24 & D7 & 2 & $1.440 .000,00$ & 0,63 \\
\hline 25 & D8 & 4 & 5.842 .055 .56 & 2,56 \\
\hline 26 & D9 & 2 & $1.594 .430,00$ & 0,70 \\
\hline 27 & D10 & 2 & $1.465 .025,00$ & 0,64 \\
\hline 28 & D11 & 2 & $786.000,00$ & 0,34 \\
\hline 29 & D12 & 2 & $767.100,00$ & 0,34 \\
\hline 30 & D13 & 2 & $1.882 .933,33$ & 0,82 \\
\hline 31 & D14 & 2 & $7.421 .208,33$ & 3,25 \\
\hline 32 & D15 & 4 & $13.345 .000,00$ & 5,84 \\
\hline 33 & $\mathrm{E}$ & 5 & $32.674 .313,00$ & 14,29 \\
\hline 34 & F & 5 & $4.490 .000,00$ & 1,96 \\
\hline 35 & $G$ & 1 & $1.200 .000,00$ & 0,52 \\
\hline 36 & $\mathrm{H}$ & 2 & $8.035 .808,33$ & 3,52 \\
\hline \multicolumn{3}{|c|}{ Total } & $228.606 .085,48$ & 100,00 \\
\hline
\end{tabular}

\section{Analisis Penelitian}

\section{Analisis Jaringan Kerja}

Pada pelaksanaan pembangunan tower $72 \mathrm{~m}$ telah diuraikan suatu kegiatan pekerjaan dengan aktivitas-aktivitas lintasan jaringan kerja CPM (Critical Path Method), bahwa lintasan ini tidak mempunyai waktu tenggang (float) oleh karena dalam pengerjaannya tidak boleh terlambat, jika terlambat akan menyebabkan keterlambatan seluruh pekerjaan kegiatan proyek. Untuk setiap perkiraan waktu dan biaya pelaksanaan seperti pada gambar 12 diperoleh waktu pelaksanaan normal adalah 45 hari kerja dengan lintasan kritis pada setiap pelaksanaan waktu normal yaitu : A1 - A2 - B1 - B2 - B3 - B5 B7 - B8 - B9 - D1 - D2 - D3 - D5 - D6 - D7 - D8 - D9 - D10 - D11 - D13 - D14 - E - F $\mathrm{H}$. Sedangkan pada gambar 14 diagram jaringan kerja dipercepat, diperoleh kegiatan pelaksanaan dengan waktu crash 36 hari kerja dengan lintasan kritis yang sama yaitu : A1 - A2 - B1 - B2 - B3 - B5 - B7 - B8 - B9 - D1 - D2 - D3 - D4 - D5 - D6 - D7 - D8 - D9 D10 - D11 - D13 - D14 - E - F dan - H.

\section{Analisis Kegiatan Normal}

Dalam pelaksanaan kegiatan waktu normal dapat di analisis bahwa pada pekerjaan : a. Pondasi tower $72 \mathrm{~m}$, b. pondasi shelter, c. pondasi pagar, dan d. jalan masuk, seperti yang telah diuraikan pada tabel 19. Bahwa waktu dan biaya berdasarkan jaringan kerja dalam kegiatan normal adalah 45 hari, dengan biaya langsung sebesar Rp 222.754.612,00. Pelaksanaan tersebut dalam keadaan normal tidak ada suatu hambatan atau gangguan yang mengakibatkan keterlambatan dalam kegiatan. Dari jaringan kerja CPM (Critical Path Method) yang dibuat menghasilkan kegiatan kritis yaitu : A1 - A2 B1 - B2 - B3 - B5 - B7 - B8 - B9 -D1 - D2 - D3 - D5 - D6 - D7 - D8 - D9 - D10 - D11 D13 - D14 - E - F dan H. Kegiatan kritis didapat dari nilai float pada masing-masing kegiatan, kegiatan tersebut memiliki nilai float nol, yang berarti kegiatan lain akan 
berpengaruh apabila kegiatan kritis tersebut mengalamai keterlambatan. Dalam kegiatan waktu normal dapat dipersentasekan bahwa dalam pelaksanaan kegiatan tersebut dengan nila bobot $100 \%$ dari nilai total Rp 222.754.612,00 untuk waktu normal, dalam realisasi pekerjaan yang dievaluasi.

\section{Analisis Kegiatan Dipercepat}

Dalam kegiatan pelaksanaan dapat dilakukan percepatan (crash program) dengan waktu dipercepat 9 hari, dari waktu normal 45 hari yaitu menjadi 36 hari kerja dengan peningkatan biaya tambahan sebesar $\mathrm{Rp} 6.125 .856,00$. dimana peningkatan biaya ini merupakan biaya penambahan jam kerja (lembur) dari waktu normal 8 jam kerja per hari ditambah 4 jam kerja lembur menjadi 12 jam kerja per harinya dengan 12 kegiatan yang dipercepat dengan lintasan kritis yaitu : A1 - A2 - B1 - B2 - B3 - B5 - B7 - B8 - B9 - D1 D2 - D3 - D4 - D5 - D6 - D7 - D8 - D9 - D10 - D11 - D13 - D14 - E - F dan H.

\section{Pembahasan Hasil Penelitian}

Perbandingan antara waktu dan biaya pada kondisi normal dan percepatan tersebut diperoleh alternative waktu pelaksanaan yang optimal untuk pembangunan tower $72 \mathrm{~m}$ tersebut, dari kegiatan yang telah diuraikan dengan 36 kegiatan pelaksanaan dengan waktu optimal didapat 36 hari kerja dimana kegiatan tersebut lebih cepat 9 hari dari waktu normal, dengan biaya percepatan sebesar Rp 228.606.085,00 yaitu mengalami kenaikan biaya sebesar Rp 6.125.856,00 dari biaya tambahan waktu jam kerja (lembur).

Dalam pembangunan tower $72 \mathrm{~m}$ dapat di analisis bahwa dengan adanya percepatan waktu yang optimal. Maka PT. Ciptajaya Sejahtera Abadi dapat meningkatkan pendapatan proyek, jika pelaksanaan sesuai dengan waktu yang dijadwalkan, tidak adanya keterlambatan dalam kegiatan pelaksanaan. PT. Ciptajaya Sejahtera Abadi mendapat 20 paket tower (sumber: data pendapatan proyek) bahwa dengan penelitian didapat data waktu proyek adalah 20 paket $=60$ unit tower per periode proyek dengan 8 bulan atau waktu normal 45 hari bisa menyelesaikan 40 unit tower/tahun, dengan adanya percepatan waktu 9 hari menjadi 36 hari, maka pendapatan meningkat mencapai $2.5 \%$ dari $40+10=50$ unit tower/tahun dalam 1 periode waktu pelaksanaan proyek.

\section{PENUTUP}

\section{A. Kesimpulan}

Dari permasalahan hasil penelitian dan pembahasan pada penelitian ini, kesimpulan yang dapat diambil bahwa hasil perhitungan manajemen proyek untuk penjadwalan pelaksanaan dengan metode CPM (Critical Path Method) yaitu membuat tabel aktivitas kegiatan, membuat network, menyusun jaringan kerja untuk mencari lintasan kritis, penjadwalan waktu normal dan waktu dipercepat (crash) diketahui waktu yang dibutuhkan dalam pelaksanaan normal adalah 45 hari sedangkan pada pelaksanaan percepatan (crash program) waktu yang dibutuhkan adalah 36 hari sehingga didapat efisien waktu 9 hari dengan biaya crash program adalah $\mathrm{Rp}$ 228.606.085,00 dengan peningkatan biaya tambahan cost slope sebesar Rp 6.125.856,00 Maka biaya tersebut adalah biaya yang optimal dengan waktu yang efektif serta hasil pekerjaan yang sesuai tanpa mengurangi mutu pekerjaan yang telah ditetapkan dalam standart pelaksanaan proyek.

\section{B. Saran}

Sebagai kontraktor jasa kontruksi dalam pembangunan sarana penunjang tower telekomunikasi akan lebih terarah dari perencanaan awal yang standart. Apabila pelaksanaan dalam pembangunan tower telekomunikasi tersebut diperoleh suatu acuan perkiraan mengenai penjadwalan, pengorganisasian, pengelolaan dan pengawasan dalam kegiatan proyek, harus menerapkan manajemen proyek yang baik sehingga sesuai dengan jadwal (schedule) waktu serta anggaran yang ditetapkan dengan biaya yang lebih optimal, sehingga dapat diperoleh suatu angka 
dan biaya yang bisa diterima oleh pihak pelaksana maupun pihak klien atau rekanan dalam suatu perencanaan, pengembangan dan pelaksanaan proyek.

Adapun saran mengenai hasil penelitian ini :

1. Bagi perusahaan agar dapat melaksanakan proyek yang tepat dengan waktu dan biaya yang optimal, perusahaan harus melakukan pengawasan pada kegiatan kegiatan kritis.

2. Dalam pembuatan network dan daftar aktivitas dibuat sejelas mungkin sehingga tidak terjadi kesalahan dalam membuat penjadwalan proyek.

3. Untuk Standarisasi waktu penjadwalan dalam pembangunan tower 72 meter dapat dipakai waktu pelaksanan yaitu 36 hari sebagai alternatif yang dipilih waktu proyek. Pelaksanaan tersebut dalam keadaan normal tidak ada suatu hambatan atau gangguan yang mengakibatkan keterlambatan

dalam kegiatan.

DAFTAR PUSTAKA

1. Abrar Husen. 2010. "Manajemen Proyek : Perencanaan, Penjadwalan danPengendalian Proyek"

2. A. Koolma, C.J.M. Van De Schoot. 1988. Manajemen Proyek. Penerbit Universitas Indonesia Press.

3. Asiyanto. 2010. Construction Project Cost Management. - Cet.3-Jakarta. Pradnya Paramita.

4. Ardian. 2005. Manajemen Proyek Penjadwalan Pembangunan Gedung Penerbit Universitas Negeri Semarang.

5. Aziz Salimi. 2006. "Penerapan Manajemen Proyek pada Gedung Java Design Center Semarang"

6. Bachtiar Ibrahim. 2001. Rencana dan Estimate Real Of Cost. - Cet.3-Jakarta : Bumi Aksara

7. Bernard W. Taylor III. 2005. Management Science. - Edisi Delapan-Jakarta : Penerbit Salemba Empat

8. C. Trihendradi. 2008. Microsoft Project 2007 : Langkah Cerdas Merencanakan, Menjadwalkan, dan Mengontrol Proyek. Edisi 1. Yogyakarta: Penerbit Andi

9. Diyan Herwansyah. 2010. Estimate Anggaran Biaya Konstruksi dan Rencana Penjadwalan : Tahap Desain pada Pembangunan Kampus BSI Margonda- Depok. Penerbit Unniversitas Gunadarma.

10. Gunawan. 2011. "Penjadwalan dan Evaluasi Proyek" JB PT Unikom PP

11. Hadi Sutopo. 2007. Dasar Manajemen Proyek. Jakarta

12. Imam Soeharto. 1992. Manajemen Proyek Industri : Persiapan, Pelaksanaan, Pengelolaan. Jakarta : Penerbit Erlangga

13. Iman Soeharto. 1997. Manajemen Proyek : dari Konseptual Sampai Operasional. - Cet.3 Jakarta : Penerbit Erlangga

14. Imam Soherato. 1999. Manajemen Proyek. Jilid I Edisi Ke 2, Jakarta : Penerbit Erlangga

15. Miranda dan A.W. Tunggal. 2003;157. Jurnal Quality Manajemen.

16. Nurhayati. 2010. Manajemen Proyek. Edisi Pertama. Yogyakarta: Penerbit Graha Ilmu.

17. Pambudy. 2005. "Analisa Proyek Pembangunan Tower Menggunakan

18. Perbandingan Metode CPM dengan Fuzzi” Jakrta : Penerbit Universitas Sahid Pedoman Penulisan Skripsi/Tugas Akhir Universitas Indraprasta PGRI, Jakarta 2010.

19. Rahadian Galih Adiyaksa. 2011. PERT \& CPM : Metode Manajemen Proyek. Jakarta.

20. Retno Maharesi. 2011. Penjadwalan Proyek dengan Menggabungkan Metode PERT \& CPM. Penerbit Re History - Gunadarma.

21. Sukanto reksohadiprodjo.1983. Manajemen Proyek. Yogyakarta : Penerbit BPFE

22. Sugiyono. 2009. Metode Penelitian Bisnis. - Cet.14 - Bandung : Penerbit Alfabeta. 